\title{
EDITORIAL
}

Fernanda Tavares Barcelos

Universidade Federal do Rio de Janeiro (UFRJ), Rio de Janeiro, RJ, Brasil, Brasil

ftbarcelos@pep.ufrj.br
DOI: https://doi.org/10.18472/cvt.20n2.2020.1872 Redalyc: http://www.redalyc.org/articulo.oa? $\mathrm{id}=115464354012$

\section{VOLUMe 2 NÚMERo 2}

Abrimos esta edição com uma entrevista exclusiva com o arquiteto Cyro Corrêa Lyra. O entrevistado relembra sua trajetória profissional e como foi construída sua relação com o tema patrimônio, e além disso, compartilha com os leitores do CVT suas impressões sobre o futuro das políticas de preservação do patrimônio cultural.

A sessão Artigos Originais é composta por quarto textos com temas relacionados turismo, que abordam questões como justiça distributiva, trabalho produtivo, gênero e gestão cultural.

Por fim, apresentamos o dossiê temático sobre patrimônio e turismo, organizado por pesquisadores do curso de turismo da Universidade Federal do Estado do Rio de Janeiro (UNIRIO) em parceria com o CVT. A sessão é composta por 5 artigos originais e tem como proposta a reunião de reflexões sobre a relação entre turismo, patrimônio e outros temas como urbanismo, cidades, mobilidade, paisagem e meio ambiente.

Boa leitura!

\section{Fernanda Tavares Barcelos}

Doutoranda em Engenharia de Produção (COPPE/UFRJ)

Editora Executiva CVT 